\title{
\begin{tabular}{l|l} 
Mibraries & DSpace@MIT
\end{tabular}
}

\author{
MIT Open Access Articles
}

\section{A System-Level Generic Model of Water Use at Power Plants and its Application to Regional Water Use Estimation}

The MIT Faculty has made this article openly available. Please share how this access benefits you. Your story matters.

Citation: Rutberg, Michael J., Anna Delgado, Howard J. Herzog, and Ahmed F. Ghoniem. “A System-Level Generic Model of Water Use at Power Plants and Its Application to Regional Water Use Estimation." Proceedings of the ASME 2011 International Mechanical Engineering Congress \& Exposition, 11-17 November, 2011, ASME, 2011. (C) 2011 by ASME

As Published: http://dx.doi.org/10.1115/IMECE2011-63786

Publisher: ASME International

Persistent URL: http://hdl.handle.net/1721.1/119615

Version: Final published version: final published article, as it appeared in a journal, conference proceedings, or other formally published context

Terms of Use: Article is made available in accordance with the publisher's policy and may be subject to US copyright law. Please refer to the publisher's site for terms of use. 


\section{A SYSTEM-LEVEL GENERIC MODEL OF WATER USE AT POWER PLANTS AND ITS APPLICATION TO REGIONAL WATER USE ESTIMATION}

\author{
Michael J. Rutberg \\ Massachusetts Institute of Technology \\ Cambridge, MA, USA
}

Howard J. Herzog

Massachusetts Institute of Technology

Cambridge, MA, USA

\author{
Anna Delgado \\ Massachusetts Institute of Technology \\ Cambridge, MA, USA
}

\author{
Ahmed F. Ghoniem \\ Massachusetts Institute of Technology \\ Cambridge, MA, USA
}

\section{ABSTRACT}

The withdrawal and consumption of water at electricity generation plants, mainly for cooling purposes, is a significant component of the energy water nexus in the US. The existing field data on US power plant water use, however, is of limited granularity and poor quality, hampering efforts to track industry trends and project future scenarios. Furthermore, there is a need for a common quantitative framework on which to evaluate the potential of the many technologies that have been proposed to reduce water use at power plants.

To address these deficiencies, we have created a systemlevel generic model (S-GEM) of water use at power plants that applies to fossil, nuclear, geothermal and solar thermal plants, using either steam or combined cycles. The S-GEM is a computationally inexpensive analytical model that approximately reflects the physics of the key processes involved and requires a small number of input parameters; the outputs are water withdrawal and consumption intensity in liters per kilowatt-hour.

Data from multiple sources are combined to characterize value distributions of S-GEM input parameters across the US, resulting in refined estimates of water use with quantified uncertainties. These estimates are then validated against typical values from the literature and against an existing field data set. By adjusting S-GEM input values or value distributions, any number of hypothetical scenarios can be rapidly evaluated. As an example, we focus here on technology evaluation, expressing proposed technological improvements in terms of S-GEM input parameters, then comparing their projected effects on overall water withdrawal and consumption intensities.

\section{INTRODUCTION}

In many regions of the world, water use at power plants, predominantly for cooling, has a significant effect on the overall water supply and on the ecological health of surface water bodies. These regional concerns are manifested in the regulations that govern power plant construction and operation. In some instances, permits for proposed plants have been denied because of water availability concerns or potentially adverse effects on aquatic life. In other instances proposed plants have opted for designs which include cooling systems that use less water but cost more and result in lower plant efficiency, or existing plants have been retrofitted with such cooling systems. During droughts, there have been cases in which generation plants have shut down because remaining operational would have left them in noncompliance with water use regulations. Water use at power plants is thus an issue that affects regional ecology and security of supply of both water and electricity. [1]-[4]

The importance of power plant water use ${ }^{1}$ is increasingly recognized, and several efforts have been made to analyze power plant water use in the US based on field data. Yang and Dziegielewski [5] performed statistical regressions on a water use dataset collected via survey from generators by the US DOE Energy Information Administration (EIA). The study's objective was to identify major determinants of water withdrawal and

1 In discussing water use, it is important to distinguish between withdrawal and consumption. "Withdrawal" refers to water taken from a watershed or aquifer, irrespective of whether it is ultimately discharged back to the watershed. "Consumption" refers to water withdrawn that is specifically not discharged back to the watershed. In this paper, the term "water use" refers generically to both withdrawal and consumption. 
consumption in terms of fuel types, cooling system types, operation conditions, and water sources.

Feeley et al. [6] of the DOE National Energy Technology Laboratory (NETL) developed twenty-five-year forecasts of thermoelectric water use in the US using a set of "model plant profiles," essentially categories broken out by plant and cooling system configuration. For each profile, an associated water withdrawal and consumption factor was calculated, drawing on information from several sources but notably using EIA survey data to estimate cooling system water use factors. Regional water use was then projected under various scenarios, specifying electricity demand, generation mix (in terms of the model plants), and penetration of water use reduction technologies.

In a similar study, King, Duncan and Webber [7] projected power plant water use for the state of Texas over a ten-year timeframe. Their analysis was resolved to the level of individual plants and drew on field data from state agencies where available. Where data was unavailable, default withdrawal and consumption factors were used, estimated with input from industry and regulatory stakeholders.

Data-focused research on power plant water use, however, has been hampered by the limited granularity and poor quality of the available US field data. The two principal nation-wide sources of power plant water use data, respectively published by the US EIA and US Geological Survey (USGS), do not capture seasonal or diurnal variation in plant water use and are acknowledged to suffer from significant inaccuracies, inconsistency, and incompleteness [4],[7]. The US fleet contains a wide variety of power plant configurations, and there are currently no standardized methods for measuring or estimating water usage.

Model-focused research on water use at power plants has revolved around detailed reference models of individual plants. A series of studies [8]-[10] published by NETL used detailed process models of state-of-the-art fossil-fuel power plants to benchmark various aspects of plant performance, including water use. The US DOE National Renewable Energy Laboratory (NREL) [11] took a similar approach to assessing water use in parabolic trough concentrated solar plants. The Integrated Environmental Control Model (IECM), a fossil-fuel power plant model developed by Rubin et al. [12], includes a water use submodel; recent work by Zhai [13],[14] applies IECM to assessing the effect of carbon capture on water use.

Because of the targeted nature and fine level of detail of these models, however, it is difficult to apply them generically to generate estimates of regional power plant water use or to evaluate the potential effects of new technologies or policies.

This paper describes a system-level generic model (SGEM) of power plant water use that was developed to address these deficiencies. The S-GEM applies to fossil, nuclear, geothermal and solar thermal plants, using either steam or combined cycles. Drawing on related treatments in the literature (Maulbetsch [15], Zhai [16]), the S-GEM was developed with the objectives of capturing the essential physics of the processes involved while minimizing computational complexity and number of input parameters. The basis of input parameters was selected such that each parameter has a clear physical meaning that can be related to plant operating conditions and performance metrics, ideally those that are specified for large numbers of plants in readily-available datasets.

After developing the system-level generic model, this paper presents an application of the S-GEM to US power plant water consumption estimation, using a recent EIA dataset and other sources. The paper concludes with an illustration of how the SGEM serves as a quantitative framework for evaluating the effects of changing technology on water use at power plants.

\section{THE SYSTEM-LEVEL GENERIC MODEL}

The outputs of the S-GEM are values for water withdrawal and water consumption intensity, expressed in L/MWh. These intensities represent the ratio of the volume of water withdrawn or consumed to the net electrical energy produced.

At the highest level, the S-GEM divides water use intensity $I$ into cooling use intensity $I_{\text {cool }}$ and process use intensity $I_{\text {proc }}$ :

$$
I=I_{\text {cool }}+I_{\text {proc }}
$$

For most plants with once-through or wet tower cooling systems, $I_{\text {cool }}$ is larger than $I_{\text {proc }}$ by approximately an order of magnitude (and by much more in the case of once-through cooling withdrawals). The S-GEM therefore leaves $I_{\text {proc }}$ as a standalone coefficient reflecting the water use of all noncooling processes in the plant, net of any internal recycling streams. For example, a non-cooling process whose wastewater was then used as makeup water for the cooling system would not count towards $I_{\text {proc }}$. Similarly, a non-cooling process whose water source consisted of cooling tower blowdown (see next section) would not count towards $I_{\text {proc }}$. For the purposes of the S-GEM, $I_{\text {proc }}$ is considered the same for both withdrawal and consumption; it is assumed that any non-cooling process wastewater streams discharged to the watershed (as opposed to evaporated or recycled) are negligible.

To determine $I_{\text {cool }}$, it is necessary to characterize the waste heat load on the cooling system. A Sankey diagram showing the energy flow for a generic thermoelectric power plant is shown below in Figure 1. Referencing the Sankey diagram, the net efficiency $\eta_{\text {net }}$ can be defined

$$
\eta_{n e t}=\frac{\dot{E}_{n e t}}{\dot{Q}_{\text {input }}}
$$

where $\dot{E}_{n e t}$ is net electricity generation rate and $\dot{Q}_{\text {input }}$ is the rate of thermal input to the plant, both in units of MW. The dimensionless coefficient $k_{o s}$, representing the fraction of heat lost to sinks other than the cooling system, is defined

$$
k_{o s}=\frac{\dot{Q}_{o s}}{\dot{Q}_{\text {input }}}
$$




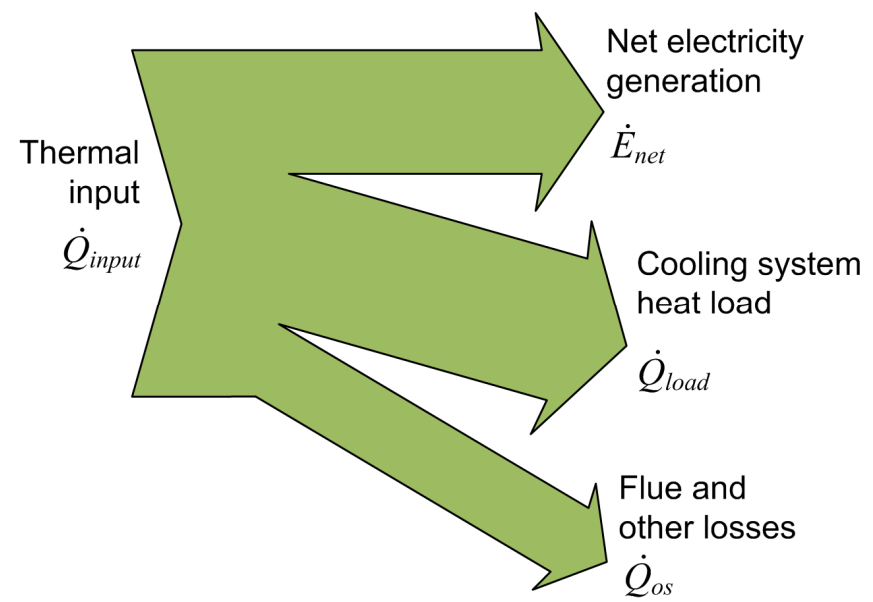

\section{FIGURE 1: HEAT FLOW THROUGH A GENERIC STEAM- CYCLE OR COMBINED-CYCLE POWER PLANT}

where $\dot{Q}_{o s}$ is the heat per unit time lost up the flue and to other sinks, in units of MW. The heat loss mechanisms encompassed by $\dot{Q}_{o s}$ include heat rejected directly to the atmosphere (not counting any such heat transfer in the cooling system) and heat lost due to a difference in sensible+latent enthalpies ${ }^{2}$ of the input and output streams.

The heat load on the cooling system $\dot{Q}_{\text {load }}$ may then be expressed as

$$
\dot{Q}_{\text {load }}=\dot{Q}_{\text {input }}\left(1-\eta_{\text {net }}-k_{\text {os }}\right)
$$

The two most common means of rejecting waste heat at US power plants are wet tower cooling systems and once-through cooling systems [6]. The mechanisms of water use in these two system types are quite different, so a separate version of the $\mathrm{S}$ GEM was developed for each.

\section{S-GEM for wet tower-cooled plants}

Wet tower cooling (see Figure 2) uses a recirculating loop of cooling water. In a typical cooling tower, hot water from the condenser and any other heat loads flows into the top of the tower. This hot water is sprayed onto the "fill," a block of lattice-like material that increases the surface area of the flow down through the tower. At the same time, a fan or natural draft draws air from the bottom of the tower up through the fill and out to the environment.

The flow of air and water acts as a heat exchanger, with convective, or "sensible," heat transfer from the water to the air. Moreover, a small fraction of the water evaporates as it makes

2 In the case of power plants involving combustion, a difference in "sensible+latent enthalpies" of the input and output streams refers to the difference in total enthalpies, net of the difference in enthalpies of formation that is accounted for by the heating value of the fuel as $\dot{Q}_{\text {input }}$. As a rule, the sensible+latent enthalpy of the output streams (e.g. hot flue gases) is larger than that of the input streams, resulting in a positive contribution to $k_{o s}$. However, it is possible for the output streams to have lower sensible+latent enthalpy than the input streams, if for example the plant implements a carbon capture process which outputs liquid $\mathrm{CO}_{2}$. If this reverse difference is sufficiently large, $k_{o s}$ may even have a negative value.

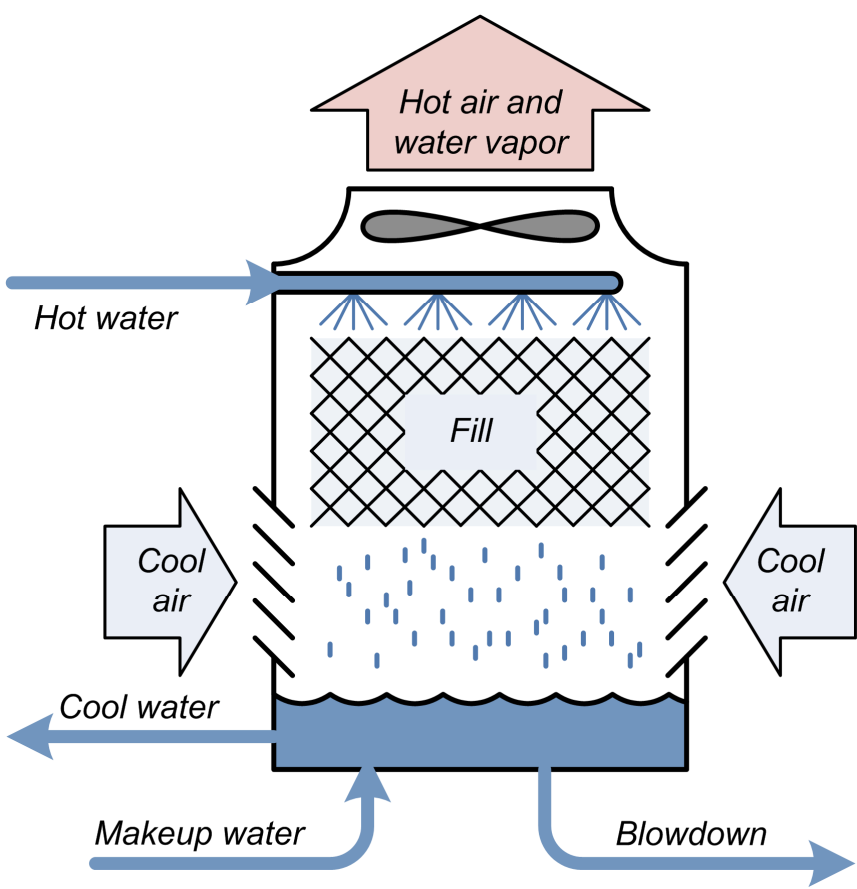

FIGURE 2: WET COOLING TOWER (INDUCED DRAFT)

its way down through the tower, and the latent heat of this evaporation cools the remaining water as well. The cooled water collects at the bottom of the tower, from where it is pumped back to the condenser and other heat loads.

Evaporation from the cooling tower is the principal mechanism through which water is consumed. In addition, smaller amounts of water are purged from the cooling water circuit to avoid build-up of harmful contaminants. This "blowdown" water may be evaporated in holding ponds (in which case it is consumed) and/or discharged to the watershed (in which case it is not counted as consumed). A third water consumption mechanism is "drift," spray that leaves the tower as liquid, but this may be considered negligible [15].

The fraction of heat load rejected through sensible heat transfer is denoted here as $k_{\text {sens }}$, and depends on the design of the cooling tower and on the temperature and humidity of the incoming air. The evaporation losses $\dot{w}_{\text {evap }}$ in units of $\mathrm{kg} / \mathrm{s}$ can then be expressed as

$$
\dot{w}_{\text {evap }}=\frac{\dot{Q}_{\text {load }}\left(1-k_{\text {sens }}\right)}{h_{f g}}
$$

where $h_{f g}$ is the latent heat of vaporization of water, 2.454 $\mathrm{MJ} / \mathrm{kg}$ at $20^{\circ} \mathrm{C}^{3}$

In industry, $k_{\text {sens }}$ is often defined implicitly using a relationship between evaporation losses $\dot{w}_{\text {evap }}$ and circulating water flow rate $\dot{w}_{\text {circ }}$ :

$$
\dot{w}_{\text {evap }}=k_{\text {evap }} \dot{w}_{\text {circ }}
$$

\footnotetext{
${ }^{3}$ Latent heat of water is approximately constant over the temperature
} ranges of interest $\left( \pm 2 \%\right.$ over $\left.0-40^{\circ} \mathrm{C}\right)$ 


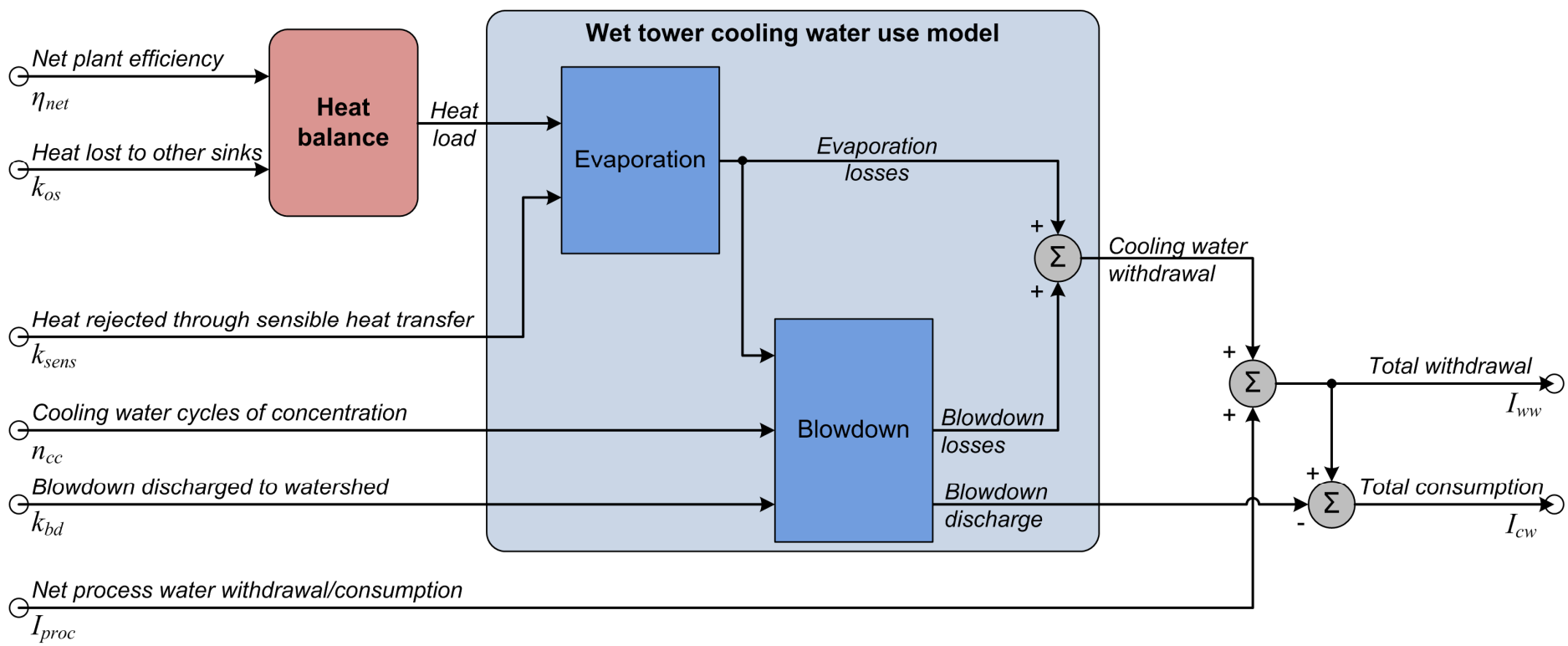

FIGURE 3: BLOCK DIAGRAM OF S-GEM FOR WET TOWER-COOLED POWER PLANT

The dimensionless constant $k_{\text {evap }}$ that relates evaporation losses to circulating water flow rate can be used to determine $k_{\text {sens }}$, by noting that for a given tower inlet-outlet temperature difference ("range") of $\Delta T$ in ${ }^{\circ} \mathrm{C}$,

$$
\dot{w}_{\text {circ }}=\frac{\dot{Q}_{\text {load }}}{c_{p} \Delta T}
$$

where $c_{p}$ is the specific heat of water, $4.184 \times 10^{-3} \mathrm{MJ} / \mathrm{kg}-\mathrm{K}$ at $20^{\circ} \mathrm{C}$. ${ }^{4}$ The sensible heat transfer coefficient $k_{\text {sens }}$ can be related to the evaporation coefficient $k_{\text {evap }}$ by combining equations 5,6 and 7 to yield

$$
k_{\text {sens }}=1-k_{\text {evap }} \frac{h_{f g}}{c_{p} \Delta T}
$$

Industry rules of thumb relate $k_{\text {evap }}$ to cooling tower range $\Delta T$, for example $k_{\text {evap }}=1 \% \times \Delta T / 7^{\circ} \mathrm{C}$ [17]. These approximations implicitly assume that $k_{\text {sens }}$ is constant.

The rate of blowdown $\dot{w}_{\text {blowdown }}$ can be related to the rate of evaporation $\dot{w}_{\text {evap }}$ in terms of the number of cycles of concentration $n_{c c}$, a parameter that describes the concentration of impurities in the circulating water relative to that of the makeup water.

$$
\dot{w}_{\text {blowdown }}=\dot{w}_{\text {evap }}\left(\frac{1}{n_{c c}-1}\right)
$$

Derivations of this relation appear in [15] and [16], so it is not presented here. The purer the input stream, the more cycles

\footnotetext{
${ }^{4}$ Specific heat of water is approximately constant over the temperature ranges of interest $\left(+0.5 /-0.1 \%\right.$ over $\left.0-40^{\circ} \mathrm{C}\right)$.
}

of concentration can be tolerated before mineral impurities reach unacceptable levels; typical values for $n_{c c}$ in the US fall between 2 and 10 [8],[18].

Combining equations 4,5 , and 9 , it can be seen that the total cooling tower water loss $\dot{w}_{\text {cool }}$ from evaporation and blowdown in units of $\mathrm{kg} / \mathrm{s}$ is equal to

$$
\dot{w}_{\text {cool }}=\dot{Q}_{\text {input }}\left(1-\eta_{\text {net }}-k_{\text {os }}\right) \frac{\left(1-k_{\text {sens }}\right)}{h_{f g}}\left(1+\frac{1}{n_{c c}-1}\right)
$$

Converting the above into an expression for cooling water withdrawal intensity in $\mathrm{L} / \mathrm{MWh}$ is accomplished by dividing through by net electricity generation $\dot{E}_{n e t}$ and water density $\rho_{w}$ $\left(0.9982 \mathrm{~kg} / \mathrm{L} \text { at } 20^{\circ} \mathrm{C}\right)^{5}$, and multiplying by 3600 to convert between seconds and hours. Adding the resulting expression to the non-cooling process intensity coefficient $I_{\text {proc }}$ yields the final model for wet tower-cooled plant withdrawal:

$I_{w w}=3600 \frac{\left(1-\eta_{\text {net }}-k_{o s}\right)}{\eta_{\text {net }}} \frac{\left(1-k_{\text {sens }}\right)}{\rho_{w} h_{f g}}\left(1+\frac{1}{n_{c c}-1}\right)+I_{p r o c}$

For a wet tower-cooled power plant, the delta between withdrawal and consumption hinges on how the cooling water blowdown is dispatched. At the extreme is Zero Liquid Discharge (ZLD) in which none of the blowdown is discharged back to the watershed, in which case withdrawal and consumption are identical. If some fraction $k_{b d}$ of the blowdown is treated and discharged, however, the S-GEM equation for cooling system water consumption becomes

\footnotetext{
${ }^{5}$ Density of water is approximately constant over the temperature ranges of interest $\left(+0.2 /-0.6 \%\right.$ over $\left.0-40^{\circ} \mathrm{C}\right)$
} 


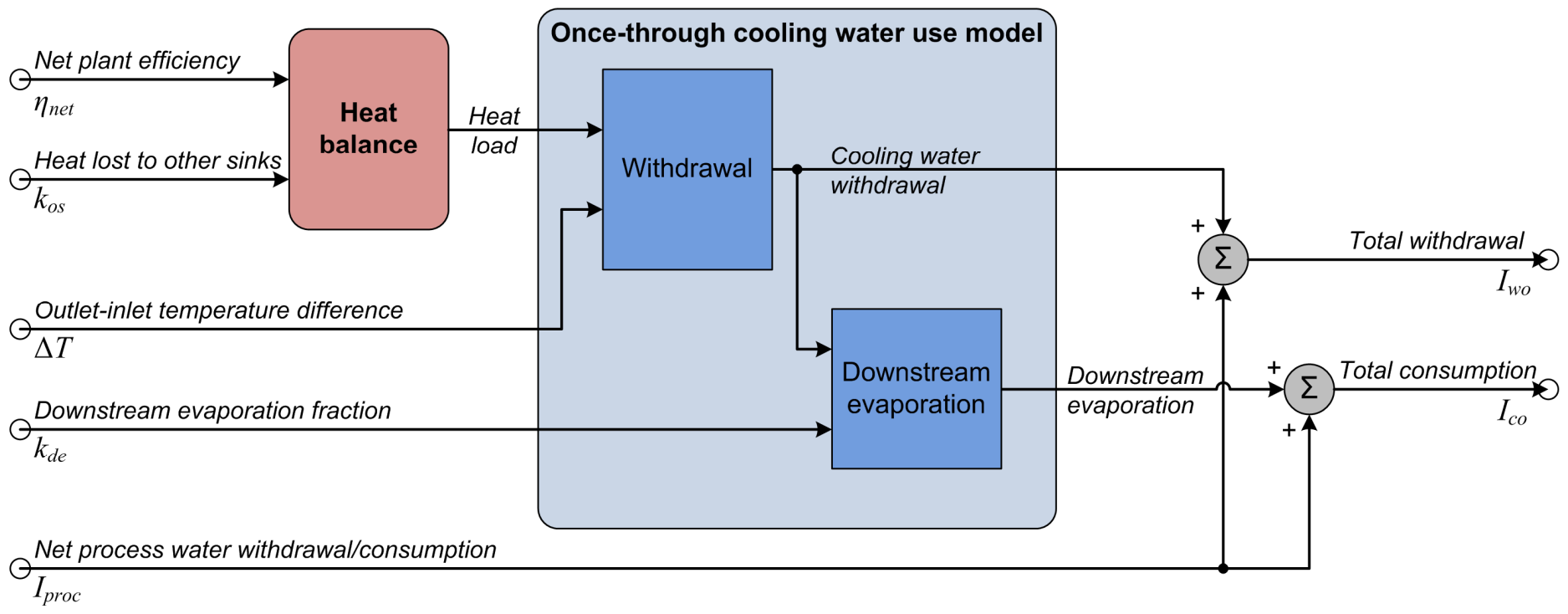

FIGURE 4: BLOCK DIAGRAM OF S-GEM FOR ONCE-THROUGH COOLED POWER PLANT

$I_{c w}=3600 \frac{\left(1-\eta_{n e t}-k_{o s}\right)}{\eta_{n e t}} \frac{\left(1-k_{\text {sens }}\right)}{\rho_{w} h_{f g}}\left(1+\frac{1-k_{b d}}{n_{c c}-1}\right)+I_{p r o c}$

assuming that $I_{\text {proc }}$ is the same for both withdrawal and consumption as discussed above. The overall model is diagrammed in Figure 3.

\section{S-GEM for once-through-cooled plants}

Once-through cooling, sometimes called open or openloop cooling, involves withdrawing water from a surface water body, running it past a heat exchanger where it takes on the waste heat, and discharging it to the same water body, now some degrees warmer. The mechanism for water consumption in once-through cooling systems is increased evaporation due to the higher temperature of the discharged water. While this evaporation does not always occur within the physical boundaries of the plant, it is attributable to the cooling system and thus is often included in water consumption analyses.

The system-level generic model for once-through cooling can be developed by realizing that the flow rate of the oncethrough cooling water in $\mathrm{kg} / \mathrm{s}$ can be expressed as

$$
\dot{w}_{\text {open }}=\frac{\dot{Q}_{\text {load }}}{c_{p} \Delta T}
$$

where $\Delta T$ is the inlet/outlet temperature difference of the cooling water. Combining equations 4 and 13 ,

$$
\dot{w}_{\text {open }}=\dot{Q}_{\text {input }}\left(1-\eta_{\text {net }}-k_{\text {os }}\right)\left(\frac{1}{c_{p} \Delta T}\right)
$$

Dividing through by net electricity generation $\dot{E}_{n e t}$ and water density $\rho_{w}$, multiplying by 3600 to convert between seconds and hours, and adding the non-cooling process intensity coefficient $I_{\text {proc }}$ yields

$$
I_{w o}=3600 \frac{\left(1-\eta_{\text {net }}-k_{o s}\right)}{\eta_{\text {net }}} \frac{1}{\rho_{w} c_{p} \Delta T}+I_{\text {proc }}
$$

To obtain an expression for consumption, the "downstream evaporation" coefficient $k_{d e}$ is introduced, representing the fraction of discharged water that undergoes forced evaporation as a result of having been warmed. The value of $k_{d e}$ is on the order of $1 \%[18]$. Then

$$
I_{c o}=3600 \frac{\left(1-\eta_{\text {net }}-k_{o s}\right)}{\eta_{\text {net }}} \frac{k_{d e}}{\rho_{w} c_{p} \Delta T}+I_{\text {proc }}
$$

assuming that $I_{\text {proc }}$ is the same for both withdrawal and consumption. The overall model is diagrammed in Figure 4.

\section{REGIONAL WATER CONSUMPTION ESTIMATION}

The system-level generic model may be applied to the estimation of regional water use if the distributions of S-GEM input parameters over the region of interest are wellcharacterized. Alternatively, input parameters can be estimated on a plant-by-plant basis if relevant plant data exists, and the resulting water use values summed over the region. As a preliminary validation of this approach, the 2009 EIA- 860 and EIA-923 datasets [19],[20], respectively containing specifications and operations data from the US generation fleet, were used to produce plant-by-plant estimates of water consumption for wet tower-cooled fossil fuel and nuclear plants. These S-GEM-generated results were then compared to water 


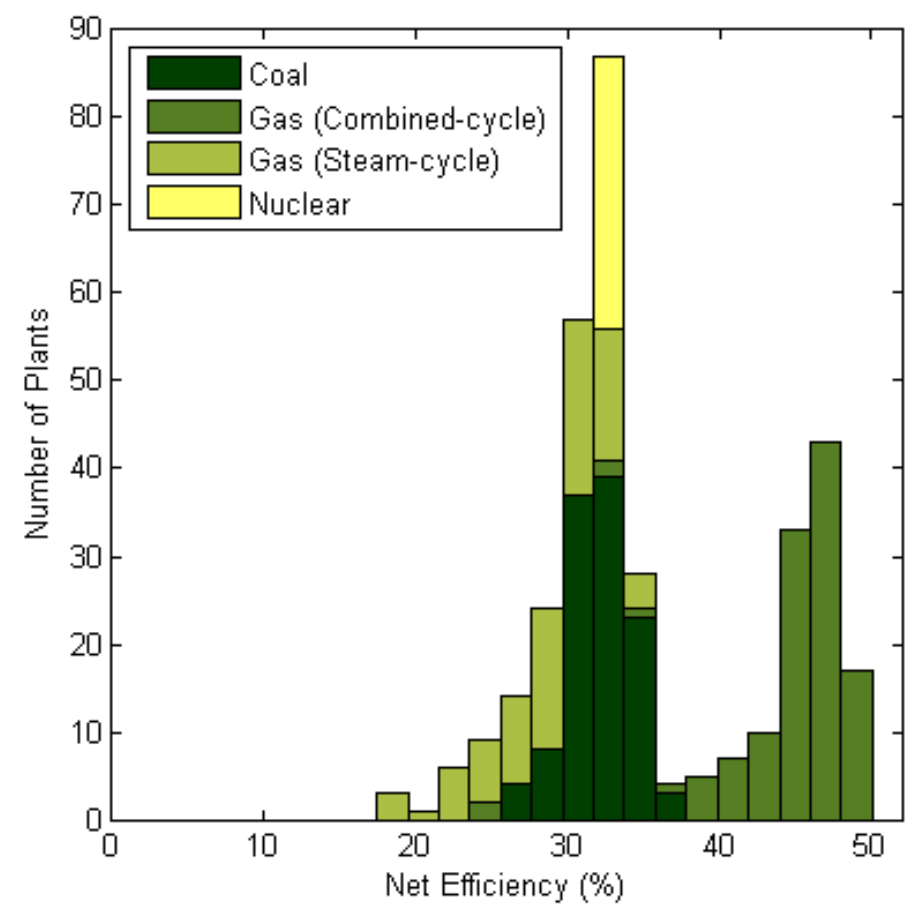

FIGURE 5: HISTOGRAM OF PLANT NET EFFICIENCIES IN 2009 EIA-923 DATASET

consumption intensities presented in a recent meta-study of water use at power plants by Macknick et al. of DOE-NREL [3]. In addition, the S-GEM results were compared site-by-site to the cooling water consumption values reported by generators on form EIA-923.

To reduce the likelihood of gross uncertainty in the reported EIA-923 operations data, the total set of US plants was first filtered to retain plants with steam cycles or combined cycles that use only wet towers ${ }^{6}$ for cooling. Plants with zero or negative net generation for the year were eliminated. Combined-heat-and-power (CHP) plants and non-utility plants were also eliminated, as the difficulty of separately attributing fuel to electrical generation and heat production in such plants makes calculated efficiency values unreliable. Collectively, the 454 retained plants, on 302 sites, account for $1400 \mathrm{TWh}$ of net generation in $2009,35 \%$ of the US total.

For each power plant in the dataset, the net efficiency $\eta_{\text {net }}$ was calculated from the EIA-923 thermal input and net electricity output values. In the case of fossil plants, the thermal input is based on the higher heating value (HHV) and quantity of fuel consumed as reported to the EIA. In the case of nuclear plants, the EIA back-calculates thermal input from net generation, assuming a net efficiency of $32.5 \%$. A histogram of the calculated efficiencies is shown in Figure 5. Three outlying plants with net efficiencies less than $15 \%$ were omitted from the dataset, and oil plants have been omitted from the figure for

${ }^{6}$ The 2009 EIA-860 dataset does not contain data on nuclear plant cooling system type, so a 2010 DOE report on nuclear power plant cooling [21] was used as a source for this information. clarity, as they contribute less than $0.5 \%$ of net generation within the dataset.

A value for $k_{o s}$ was set for each plant based on fuel and prime mover type, according to the scheme shown in Table 1. These values were derived from the energy balances of NETL reference models [9] of gas combined-cycle and subcritical pulverized coal plants by dividing the flue losses by the higher heating value of the fuel input. Oil combined-cycle plants were assumed to have the same value of $k_{o s}$ as gas combined-cycle plants, while oil and gas steam-cycle plants were assumed to have the same value of $k_{o s}$ as coal steam-cycle plants. For nuclear plants, $k_{o s}$ was assumed to be 0 , since nuclear plants have no flue losses.

Because the NETL reference models reflect state-of-the-art plants, their net efficiencies are on the high side of the corresponding distributions in Figure 5 (37\% for subcritical coal, $50 \%$ for gas combined-cycle). The energy balance of an average plant in the EIA dataset therefore differs from that of the reference model, potentially introducing some systematic error to the assumed values of $k_{o s}$. Future analyses may incorporate EIA data on flue gas temperatures, flow rates, and desulfurization systems to generate refined estimates of $k_{o s}$ on a plant-by-plant basis.

To estimate $k_{\text {sens }}$, the fraction of heat load rejected through sensible heat transfer, a correlation was developed based on the Poppe cooling tower model as implemented by Kloppers and Kroger [22]. According to this model, $k_{\text {sens }}$ depends on six cooling tower parameters: inlet air temperature, inlet air humidity, inlet water temperature, outlet water temperature, ambient pressure, and water/air mass flow ratio. Of these, $k_{\text {sens }}$

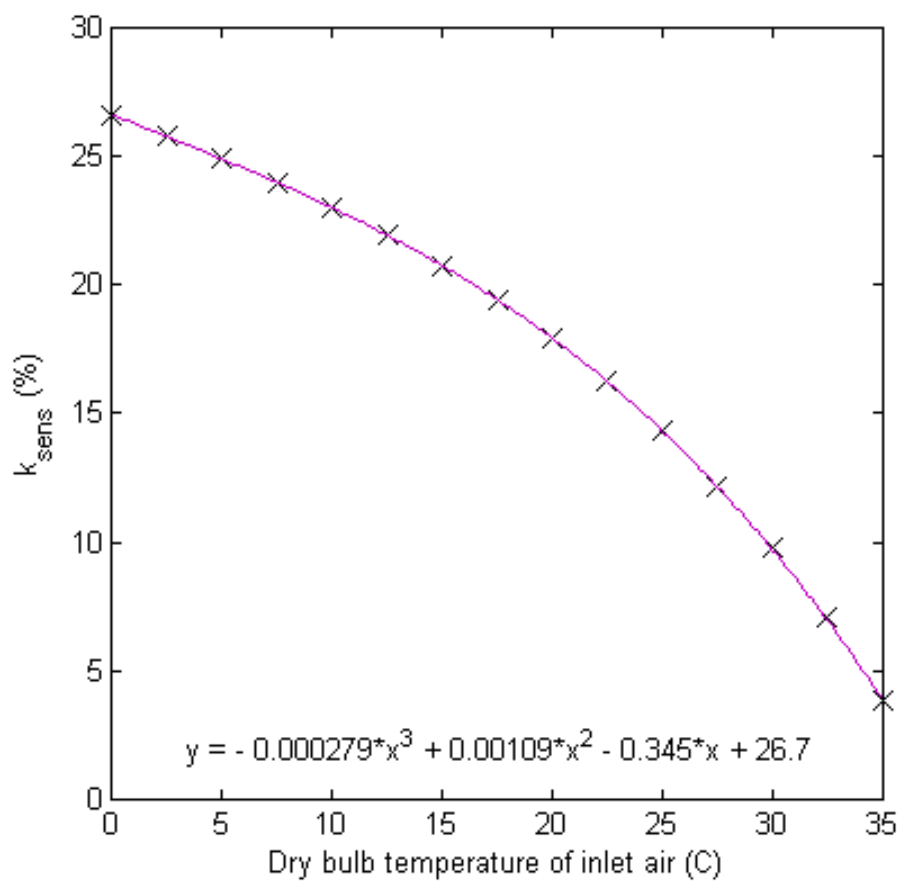

FIGURE 6: CORRELATION BETWEEN ksENS AND AMBIENT DRY BULB TEMPERATURE 
TABLE 1: S-GEM PARAMETER ESTIMATION SCHEME USED IN CALCULATION OF WATER CONSUMPTION ESTIMATES

\begin{tabular}{|c|c|c|c|}
\hline Parameter & Mean value estimation method & Data sources & $\pm 2 \sigma$ relative uncertainty \\
\hline $\begin{array}{l}\text { Net efficiency } \\
\eta_{\text {net }}\end{array}$ & $\begin{array}{l}\text { Calculated based on fuel consumed } \\
\text { and net generation }\end{array}$ & $\begin{array}{l}\text { EIA-923 database, } 2009 \\
\text { [19] }\end{array}$ & $\pm 10 \%$ \\
\hline $\begin{array}{l}\text { "Other sinks" fraction } \\
k_{o s}\end{array}$ & $\begin{array}{l}\text { Fixed value for each plant type } \\
\text { (Combined-cycle: } 0.20 \text {; Fossil steam- } \\
\text { cycle: } 0.12 \text {; Nuclear steam-cycle: } 0 \text { ) }\end{array}$ & $\begin{array}{l}\text { DOE-NETL reference } \\
\text { models [9] }\end{array}$ & $\pm 35 \%$ \\
\hline $\begin{array}{l}\text { Sensible heat rejection fraction } \\
k_{\text {sens }}\end{array}$ & $\begin{array}{l}\text { Calculated based on average air } \\
\text { temperature }\end{array}$ & $\begin{array}{l}\text { Poppe cooling tower model } \\
\text { (implementation after [22]) }\end{array}$ & $\pm 35 \%$ \\
\hline $\begin{array}{l}\text { Non-cooling process water use } \\
\text { intensity } \\
I_{\text {proc }}\end{array}$ & $\begin{array}{l}\text { Fixed value for each fuel type } \\
\text { (Oil/Coal: } 200 \mathrm{~L} / \mathrm{MWh} \\
\text { Gas/Nuclear: } 10 \mathrm{~L} / \mathrm{MWh} \text { ) }\end{array}$ & $\begin{array}{l}\text { DOE-NETL reference } \\
\text { models [9] }\end{array}$ & N/A \\
\hline
\end{tabular}

is most sensitive to inlet air temperature. A series of model runs was executed varying air temperature while holding the other tower parameters constant; ${ }^{7}$ the results were fit to a cubic equation as shown in Figure 6. To estimate the air inlet temperature for each plant, the approximate latitude and longitude of the plant were found based on 5-digit ZIP code [23], and the nearest weather station registered with the US National Climatic Data Center (NCDC) was located. The overall mean normal air temperature at that station [24] was then used to estimate $k_{\text {sens }}$ based on the cubic correlation. A similar approach to the estimation of $k_{\text {sens }}$ has been taken by Zhai [16].

For the purposes of this analysis, the blowdown discharge fraction $k_{b d}$ was assumed equal to 1 , effectively eliminating blowdown from the consumption calculation. The EIA-923 and EIA-860 datasets do not contain information on cooling water cycles of concentration $\left(n_{c c}\right)$ or blowdown discharge $\left(k_{b d}\right)$. Typically, however, plants in regions with plentiful water are able to legally discharge most of their cooling tower blowdown to the watershed (values of $k_{b d}$ approaching 1), although $n_{c c}$ may be low. Conversely, plants in regions where water is scarce may have values of $k_{b d}$ approaching 0 , but tend to run at higher $n_{c c}$ to conserve water. This inverse correlation between $n_{c c}$ and $k_{b d}$ could be expected to keep the blowdown consumption term in equation 12 to a reasonably small fraction. However, the error introduced by neglecting blowdown consumption is nonnegligible in some cases. Future analyses may incorporate assumptions about $k_{b d}$ and $n_{c c}$ based on regional trends like those described above.

Non-cooling process water consumption intensity $I_{\text {proc }}$ was set for each plant based on fuel type, according to the scheme shown in Table 1. Coal and oil plants were assumed to use wet flue gas desulfurization units, with a resulting $I_{\text {proc }}$ of about 200

${ }^{7}$ The model runs assumed standard atmospheric pressure at $0 \mathrm{~m}$ elevation, air inlet relative humidity of $60 \%$, air/water mass flow ratio of 1 , and water inlet temperature of $40^{\circ} \mathrm{C}$. The water outlet temperature was determined such that its "approach" to the air inlet wet bulb temperature was $40 \%$ of the difference between the water inlet temperature and the air inlet wet bulb temperature.
L/MWh, while nuclear and gas plants were assumed to use very little non-cooling process water, on the order of $10 \mathrm{~L} / \mathrm{MWh}$, for boiler feedwater makeup and miscellaneous uses.

After estimating the S-GEM input parameters for each plant, the water consumption intensity $I_{c w}$ was calculated using equation 12. A histogram of the results is shown in Figure 7, again omitting oil plants for clarity. Shown above the histogram are the median and extreme literature values of water consumption intensity for wet tower-cooled power plants of each type, as given in the 2011 meta-study by Macknick et al. [3]. This meta-study collected and presented estimates of water withdrawal and consumption intensity for various generation technologies in the US, taken unmodified from a comprehensive search of the published primary literature.

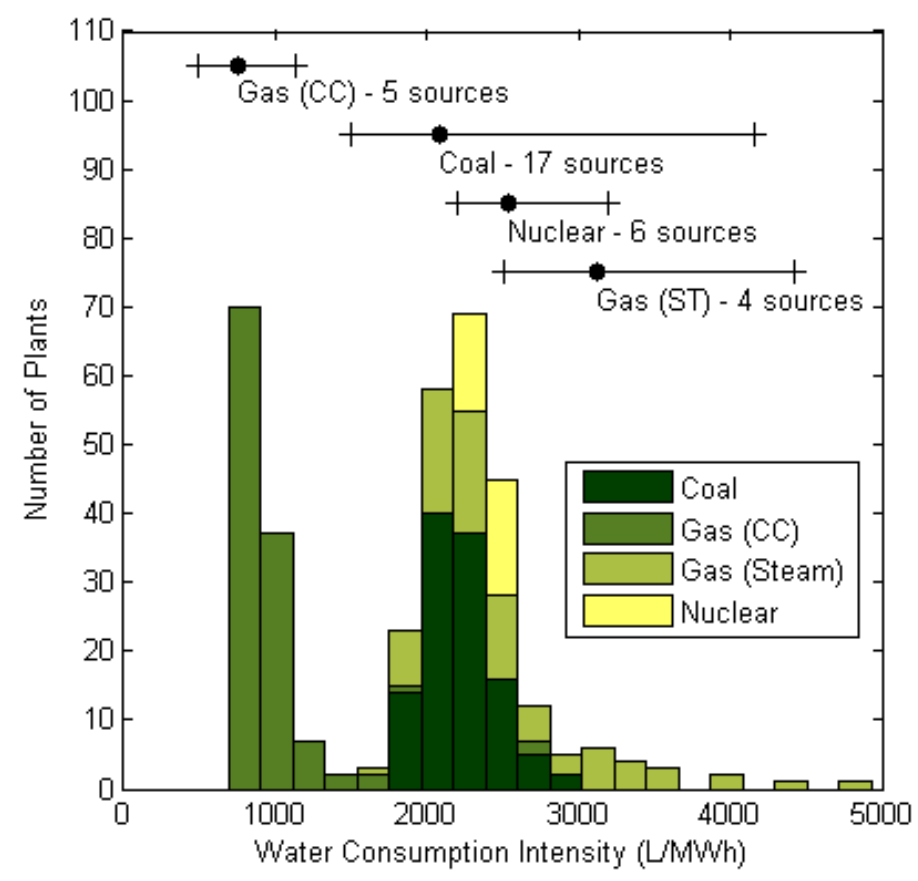

FIGURE 7: HISTOGRAM OF S-GEM ESTIMATES OF PLANT WATER CONSUMPTION INTENSITY, WITH MEDIANS AND RANGES OF VALUES FROM THE LITERATURE [3] 
For gas combined-cycle, nuclear, and coal plants, agreement between the S-GEM estimates and literature values is good. For gas steam-cycle generation (which accounts for less than $1.5 \%$ of the net generation in this dataset), the literature values fall higher than some of the S-GEM estimates. Perhaps because they are not heavily used, however, gas steamcycle plants have been less widely studied than the other three types; there are only 4 sources listed in Macknick et al. for water consumption at tower-cooled gas steam-cycle plants, and it is possible that these sources are less reliable than those for more heavily used technologies. Overall, comparison with the meta-study results suggests that the S-GEM for wet towercooled plants, as well as the methodology used to estimate SGEM input parameters in this analysis, is reasonably effective.

The S-GEM results were also compared to water consumption values reported by generators on form EIA-923. Because many generation sites run multiple plants, fuels, and cooling systems, these comparisons were made on a site-by-site basis rather than a plant-by-plant basis. A total of 182 sites employing only wet tower cooling reported water use data to the EIA in 2009, accounting for $660 \mathrm{TWh}$ of net generation. Water use data for nuclear plants has not been collected by the EIA since 2002, so this analysis included only sites with fossil plants.

The reported water consumption values nominally refer to cooling water only, so $I_{c w}$ for each plant was recalculated using equation 12 , this time with non-cooling process water use $I_{\text {proc }}$ set to 0 . The calculated cooling water consumption intensity was then multiplied by the annual net generation to obtain an estimate of total annual cooling water consumption. Cooling water consumption estimates for all plants on each site were summed to produce site-level estimates, which were then compared to the annual cooling water consumption values reported $^{8}$ on EIA-923. The results are plotted in Figure 8.

The marker types in Figure 8 indicate the basis of water rights law for the US state in which each site is located [25]. To a rough approximation, riparian law is used where water is plentiful, prior appropriation law where water is scarce. States in the eastern US typically use riparian systems, while western states use prior appropriation systems or hybrid systems including elements of both. As is evident in the figure, the sites with the greatest discrepancies between reported and predicted cooling water consumption are located in riparian states. This suggests that, on the whole, water use is not as carefully accounted at plants in these states.

An uncertainty analysis of the S-GEM cooling water consumption estimates was conducted for sites in non-riparian states. To estimate the uncertainty in the consumption intensity value, a vector of 1000 Monte Carlo input parameter sets was stochastically generated for each plant, using mean values of

\footnotetext{
${ }^{8}$ Due to an ambiguity in the instructions on form EIA-923, a significant fraction of generators report cooling water consumption in tenths of the units specified by the EIA, resulting in reported values 10 times higher than intended. Reported values higher than the corresponding S-GEM estimates by more than a factor of 5 were divided by 10 prior to inclusion in the data set.
}

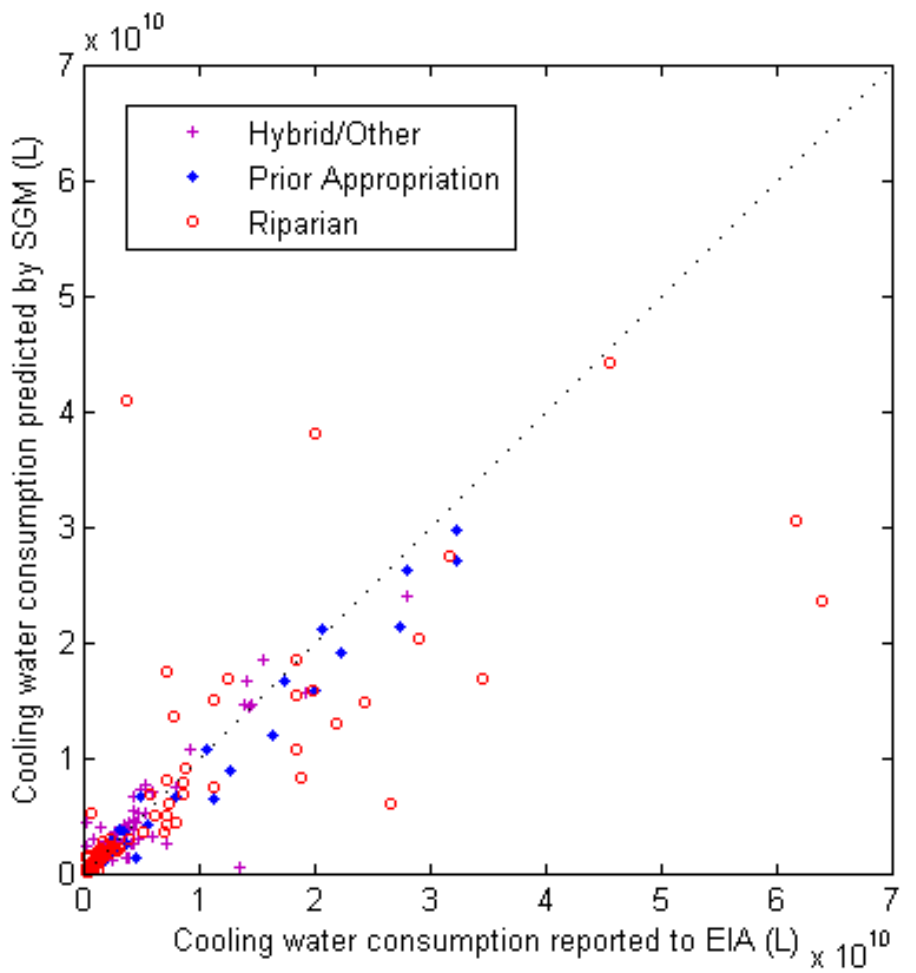

FIGURE 8: COMPARISON OF PREDICTED AND REPORTED COOLING WATER CONSUMPTION VALUES, LABELED BY WATER RIGHTS LAW SYSTEM IN EFFECT AT EACH SITE

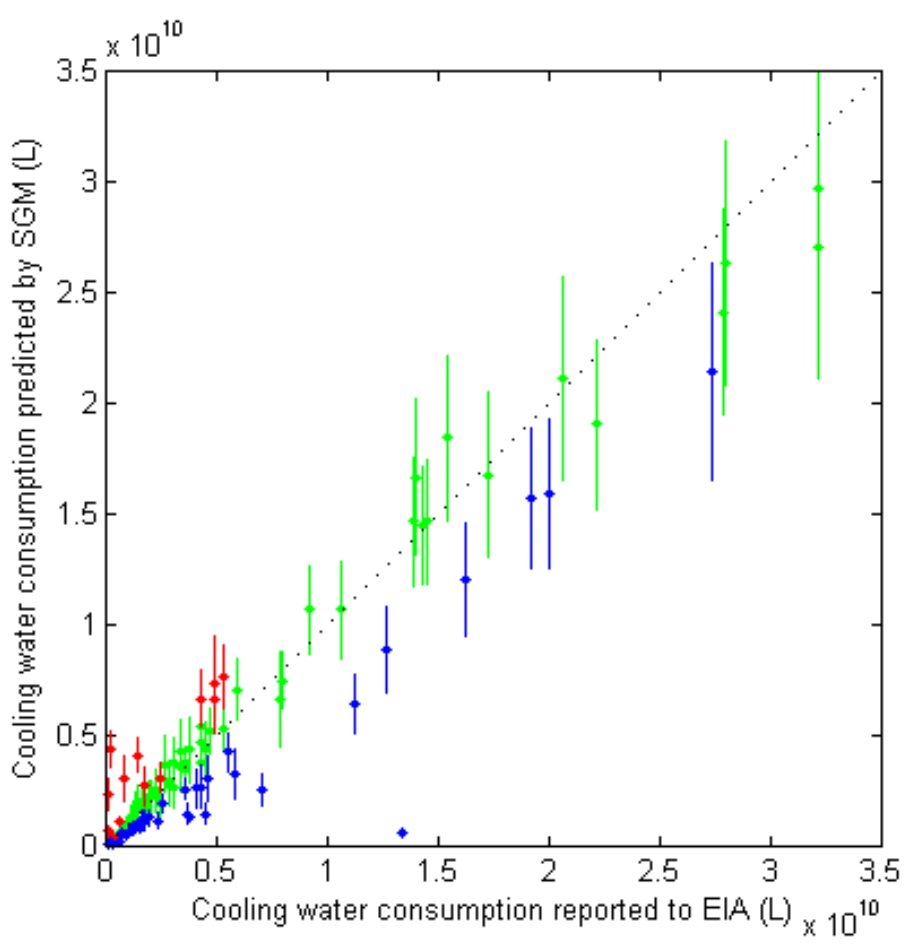

FIGURE 9: COMPARISON OF PREDICTED AND REPORTED COOLING WATER CONSUMPTION VALUES (SITES IN NONRIPARIAN STATES ONLY) 
$\eta_{n e t}, k_{o s}$, and $k_{\text {sens }}$ estimated as described above, and standard deviations prescribed according to the uncertainty scheme shown in Table 1. Equation 12 was applied to each set, and the standard deviation $\sigma$ of the resulting vector of $I_{c w}$ values was calculated. The uncertainty was defined as twice this $\sigma$ value, equivalent to a $95 \%$ confidence interval. The uncertainty on consumption intensity for each plant was multiplied by annual net generation to obtain an estimate of uncertainty on the calculated value of total annual cooling water consumption. These uncertainties were summed over all plants on each site to obtain site-level uncertainties.

Figure 9 shows the cooling water consumption estimates produced by the S-GEM, with associated uncertainties, plotted against the reported values for all sites in non-riparian states. The reported value of cooling water consumption fell within the S-GEM-predicted range for $53.4 \%$ of the sites examined (green in Figure 9); for $12.6 \%$, the reported value was too low (red) and for $34.0 \%$ the reported value was too high (blue). The linear correlation coefficient between the predicted and reported values was 0.960 .

Given that this analysis neglected consumption from cooling tower blowdown, it could be expected that the calculated consumption estimates err towards the low side. In addition, non-base-load plants are more likely to be dispatched during the daytime, and particularly during periods of hot weather, when demand is highest. The overall mean of normal air temperature used to estimate $k_{\text {sens }}$ in this analysis does not reflect this trend. This almost certainly resulted in an overestimate of effective $k_{\text {sens }}$ for many plants, and thus an underestimate of water consumption intensity.

Applying some combination of additional data and finergrained assumptions to estimate $k_{\text {sens }}, n_{c c}$, and $k_{b d}$ with greater fidelity would likely reduce the number of blue points in Figure 9. It should be stressed, however, that the uncertainty on the water consumption values reported to the EIA, while unquantified, is potentially very high [4]. The significant fraction of reported values that are out of the predicted ranges should therefore not be discouraging. Rather, one of the primary purposes of the S-GEM is to enable estimates of water consumption that draw upon reliable data with comparatively low associated uncertainties. On a regional level, water use estimates obtained using the S-GEM may be more reliable than those obtained by extrapolating field data.

\section{CONCLUSION: TECHNOLOGY ANALYSIS}

In addition to facilitating regional power plant water use estimation, the S-GEM also provides a useful framework for evaluating water use reduction technologies. As an example, Figure 10 shows a sensitivity analysis of water withdrawal intensity to four S-GEM input parameters, using a wet-cooled coal plant model [9] as the initial reference. For each plot, the parameter of interest was varied while holding the others constant, and the resulting values for $I_{w w}$ obtained using equation 11 . The dashed horizontal lines show the intensity of
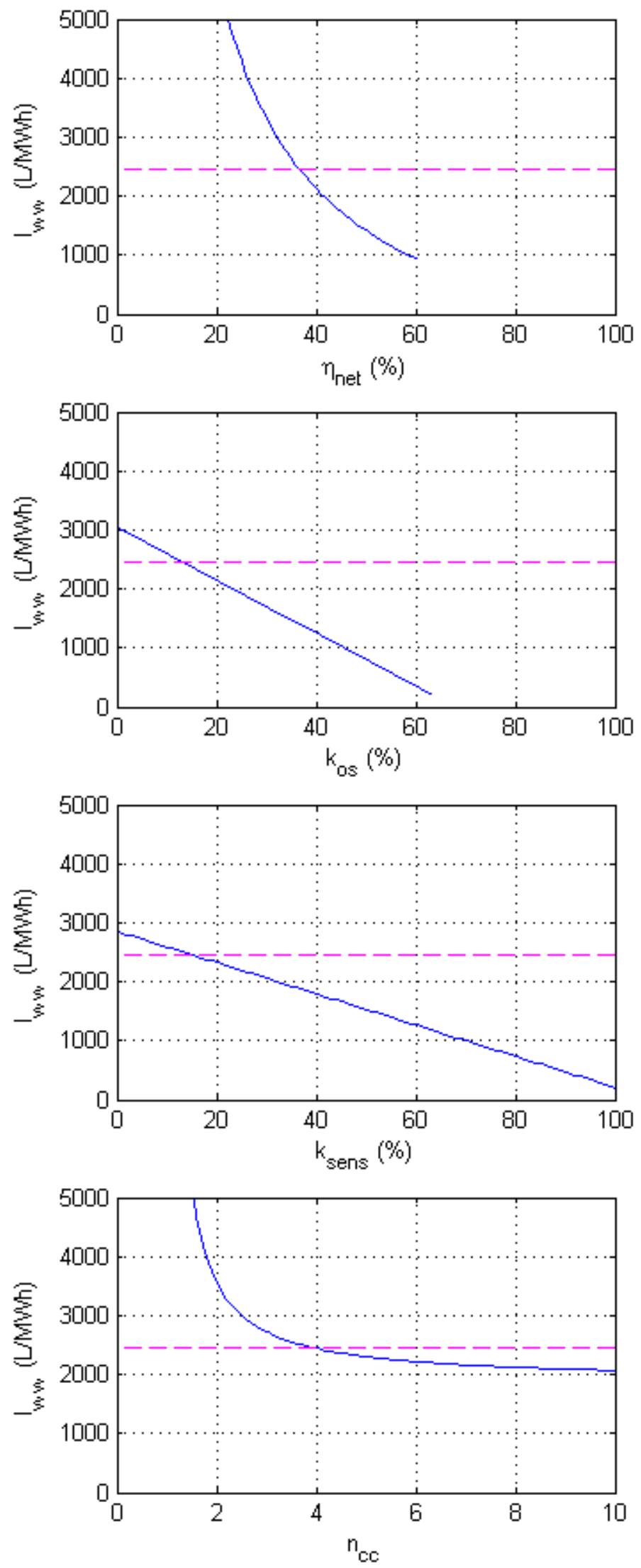

FIGURE 10: S-GEM PARAMETER SENSITIVITY ANALYSIS 
the reference case; each curve therefore crosses the dotted line at its reference case value.

Increasing efficiency $\eta_{n e t}$ is clearly a very effective way to reduce water use intensity; it both reduces heat load and increases output electricity. Increasing $k_{o s}$ by rejecting heat to alternate sinks (e.g. in some form of combined-heat-and-power facility) also decreases water use.

While $\eta_{n e t}$ and $k_{o s}$ both concern the normalized heat load on the cooling system, the parameters $k_{\text {sens }}$ and $n_{c c}$ concern the cooling system itself. If a hybrid wet/dry cooling system is used, for example, the effective value of $k_{\text {sens }}$ goes up and water withdrawal intensity goes down; in the extreme case of an aircooled system, $k_{\text {sens }}$ is equal to $100 \%$ and the only remaining water use is from non-cooling processes $\left(I_{\text {proc }}\right)$.

Treating the cooling makeup water to enable increased values of $n_{c c}$ can decrease blowdown, but this has somewhat limited scope for reducing water consumption. As discussed in the previous section, plants running at low values of $n_{c c}$ often discharge most of their cooling tower blowdown back to the watershed. Plants already running at higher values of $n_{c c}$ can obtain only incremental water savings by pushing it higher still.

This treatment of sensitivity is a simplification; the S-GEM input parameters are rarely completely independent. The interactions between parameters, however, can be incorporated into the S-GEM parameter estimation process. For a real or hypothetical power plant fleet, the S-GEM thus provides a broadly-applicable, consistent, quantitative framework for assessing how the deployment of a given technology would affect regional water withdrawal and consumption.

\section{ACKNOWLEDGEMENTS}

This research was funded by BP as part of the Energy Sustainability Challenge; their support is gratefully acknowledged. The authors would also like to thank Edward Spang for his suggestions and advice.

\section{NOMENCLATURE}

$\dot{Q}_{\text {load }} \quad$ Heat load on cooling system

[MW]

$\dot{Q}_{\text {input }} \quad$ Thermal input to power plant

[MW]

$\dot{Q}_{o s} \quad$ Heat lost to sinks other than the cooling system

$\dot{E}_{n e t} \quad$ Net electricity generated

$[\mathrm{MW}]$

$\dot{w}_{\text {circ }} \quad$ Mass flow rate of circulating cooling water

[MW]

$\dot{w}_{\text {evap }} \quad$ Rate of cooling water lost to evaporation

$[\mathrm{kg} / \mathrm{s}]$

$\dot{w}_{\text {blowdown }}$ Rate of cooling water lost to blowdown

$\dot{w}_{\text {cool }} \quad$ Total mass flow rate of cooling water lost

$\dot{w}_{\text {open }} \quad$ Rate of once-through cooling water

I Total water use intensity

$[\mathrm{kg} / \mathrm{s}]$

$[\mathrm{kg} / \mathrm{s}]$

$[\mathrm{kg} / \mathrm{s}]$

$[\mathrm{kg} / \mathrm{s}]$

$I_{\text {proc }} \quad$ Water use intensity of non-cooling processes $[\mathrm{L} / \mathrm{MWh}]$

$I_{\text {cool }} \quad$ Water use intensity of cooling processes

$I_{w w} \quad$ Water withdrawal intensity, wet

[L/MWh]

$I_{\text {wo }} \quad$ Water withdrawal intensity, once-through

[L/MWh]

$I_{c w} \quad$ Water consumption intensity, wet

[L/MWh]

$I_{c o} \quad$ Water consumption intensity, once-through $[\mathrm{L} / \mathrm{MWh}]$

$\eta_{\text {net }} \quad$ Net efficiency

$k_{o s} \quad$ Thermal input lost to non-cooling system sinks $k_{\text {sens }} \quad$ Heat load rejected through convection

$k_{b d} \quad$ Fraction of blowdown discharged to the watershed [\%]

$k_{d e} \quad$ Fraction of withdrawal that evaporates downstream [\%]

$k_{\text {evap }} \quad$ Fraction of circulating water lost to evaporation [\%]

$n_{c c} \quad$ Number of cycles of cooling water concentration [\#]

$\Delta T \quad$ Cooling range; inlet/outlet temperature difference $\left[{ }^{\circ} \mathrm{C}\right]$

$\rho_{w} \quad$ Density of water $\quad[\mathrm{kg} / \mathrm{L}]$

$h_{f g} \quad$ Latent heat of water

$c_{p} \quad$ Specific heat of water

$[\mathrm{MJ} / \mathrm{kg}]$

$[\mathrm{MJ} / \mathrm{kg}-\mathrm{K}]$

\section{REFERENCES}

[1] U.S. DOE, 2006, "Energy Demands on Water Resources: Report to Congress on the Interdependency of Energy and Water." U.S. Department of Energy, Washington, DC.

[2] Barker, B., 2007, "Running Dry at the Power Plant," EPRI Journal, Summer 2007, pp. 26-35.

[3] Macknick, J., Newmark, R., Heath, G. and Hallet, KC, 2011, "A Review of Operational Water Consumption and Withdrawal Factors for Electricity Generating Technologies," Technical Report No. NREL/TP-6A20-50900, U.S. DOE National Renewable Energy Laboratory, Boulder, CO.

[4] Mittal, A., and Gaffigan, M., 2009, "Energy-Water Nexus: Improvements to Federal Water Use Data Would Increase Understanding of Trends in Power Plant Water Use," GAO-1023, U.S. Government Accountability Office, Washington, DC.

[5] Yang, X. and Dziegielewski, B., 2007, "Water Use by Thermoelectric Power Plants in the United States," J. Amer. Water Resources Assoc., 43(1), pp. 160-169.

[6] Feeley, T.J., Skone, T.J., Stiegel, G.J., McNemar, A., Nemeth, M. Schimmoller, B., Murphy, J.T. and Manfredo, L., 2008, "Water: A Critical Resource in the Thermoelectric Power Industry," Energy, 33(1), pp. 1-11.

[7] King, C., Duncan, I. and Webber, M., 2008, "Water Demand Projections for Power Generation in Texas," Contract No. 0704830756, Texas Water Development Board, Austin, TX. [8] Klett, M.G., Kuehn, N.J., Schoff, R.L., Vaysman, V. and White, J.S., 2007, "Power Plant Water Usage and Loss Study" (May 2007 Revision), U.S. DOE National Energy Technology Laboratory, Pittsburgh, PA.

[9] NETL, 2010, "Cost and Performance Baseline for Fossil Energy Plants; Volume 1: Bituminous Coal and Natural Gas to Electricity," Technical Report No. DOE/2010/1397, U.S. DOE National Energy Technology Laboratory, Pittsburgh, PA.

[10] DiPietro, P., Gerdes, K., and Nichols, C., 2009, "Water Requirements for Existing and Emerging Thermoelectric Plant Technologies," Technical Report No. DOE/NETL-402/080108 (April 2009 Revision), U.S. DOE National Energy Technology Laboratory, Pittsburgh, PA.

[11] Turchi, C.S., Wagner, M.J. and Kutscher, C.F., 2010, "Water Use in Parabolic Trough Power Plants: Summary Results from WorleyParsons' Analyses," Technical Report No. NREL/TP-5500-49468, U.S. DOE National Renewable Energy Laboratory, Boulder, CO.

[12] Carnegie Mellon University, Integrated Environmental Control Model, http://www.cmu.edu/epp/iecm 
[13] Zhai, H. and Rubin, E.S., 2010, "Performance and Cost of Wet and Dry Cooling Systems for Pulverized Coal Power Plants With and Without Carbon Capture and Storage," Energy Policy, 38(10), pp. 5653-5660.

[14] Zhai, H. Rubin, E.S. and Versteeg, P.L., 2011, "Water Use at Pulverized Coal Power Plants with Postcombustion Carbon Capture and Storage," Environ. Sci. Technol., 45(6), pp. 24792485.

[15] Maulbetsch, J., 2004, "Comparison of Alternate Cooling Technologies for U.S. Power Plants: Economic, Environmental, and Other Tradeoffs," Technical Report No. 1005358, EPRI, Palo Alto, CA.

[16] Berkenpas, M.B., Kietzke, K., Mantripragada, H., McCoy, S., Rubin, E.S., Versteeg, P.L., and Zhai, H., 2009, "IECM Technical Documentation Updates Final Report," Contract No. DE-AC26-04NT41917, U.S. DOE National Energy Technology Laboratory, Pittsburgh, PA.

[17] ASHRAE, 2008, ASHRAE Handbook - HVAC Systems and Equipment, ASHRAE, Atlanta, GA, Chap. 39.

[18] Myhre, R., 2002, "Water \& Sustainability (Volume 3): U.S. Water Consumption for Power Production - The Next Half Century", Topical Report No. 1006786, EPRI, Palo Alto, CA.

[19] EIA, 2009, EIA-923 January - December Final, Nonutility Energy Balance and Annual Environmental Information Data, U.S. DOE Energy Information Administration, Washington, DC.

[20] EIA, 2009, EIA-860 Annual Electric Generator Report, U.S. DOE Energy Information Administration, Washington, DC.

[21] Vine, G., 2010, "Cooling Water Issues and Opportunities at U.S. Nuclear Power Plants," Technical Report No. INL/EXT10-20208, U.S. DOE Idaho National Laboratory, Idaho Falls, ID.

[22] Kloppers, J.C. and Kroger D.G., 2005, "A Critical Investigation into the Heat and Mass Transfer Analysis of Counterflow Wet-cooling Towers," Intl. J. Heat and Mass Transfer, 48(3-4), pp. 765-777.

[23] ZIP Code Download, 2011, USA 5-Digit ZIP Code Database, Premium Edition, http://www.zipcodedownload.com [24] NCDC, 2002, U.S. Daily Climate Normals 1971-2000, U.S. DOC-NOAA, National Climatic Data Center, Asheville, $\mathrm{NC}$.

[25] Schroeder, L., 2008, "USCID: Water Rights in the U.S. and Shortages," Retrieved July 27, 2011 from http://uscid.us/ $08 \mathrm{gcc} /$ Schroeder.PDF. 